develop the intermediate neurotoxic syndrome while other equally seriously intoxicated patients do not. Paraoxon polymorphism (the genetic capability of humans to detoxify organophosphates), toxic liposolubility, and interaction with other toxins, among other possibilities, would contribute to the development of the intermediate neurotoxic syndrome in people with atypica butyrylcholinesterase.

Therefore, pseudocholinesterase activity is worth studying in further epidemiological and toxicological follow up studies on pesticide intoxication, including those recommended by Steenland. ${ }^{1}$

FIDIAS E LEON-S

Clinical fellow

Department of Neurology,

University of Alabama,

Birmingham, AL 35294

USA

GUSTAVO PRADILLA

Unit of Neurology,

Department of Internal Medicine,

UIS-Santander University School of Medicine,

Bucaramanga,

Colombia

ESPERANZA VESGA

Unit of Toxicology,

Department of Basic Sciences,

UIS-Santander University School of Medicine,

Bucaramanga,

Colombia

Steenland K. Chronic neurological effect of organophosphate pesticides. BMF 1996;312:1312-3. (25 May.)

Senanayake N, Karielledde L. Neurotoxic effects of organophosphorus insecticides. An intermediate syndrome. N Eng f Med 1987;316:761-3.

3 Leon-S FE, Pradilla G, Vezga E, Gamboa N. Multisystem failure atrophy, intermediate syndrome, anticholinesterase treatment and congenital acetylcholinesterase deficiency: the linkage is puzzling. $f$ Toxicol Clin Toxicol 1996;34:245-6.

4 Rotundo RL, Fambrough DM. Function and molecular structure of acetylcholinesterase. In: Engel AG, FranziniAmstrong C, eds. Myology, basic and clinical. McGraw Hill: New York, 1994:607-23.

5 Lowestein-Lichenstein Y, Schwarz M, Glick D, NorgaardPedersen B, Zakut H, Soreq H. Genetic predisposition to adverse consequences of anti-cholinesterases in "atypical" BChE carriers. Nature Med 1995;1:1082-5.

\section{Diagnosis and management of migraine}

\section{Differential diagnosis may be different in} patients presenting to an ophthalmologist

EDITOR,-Peter J Goadsby and Jes Olesen's review of the diagnosis and management of migraine is informative. ${ }^{1}$ Patients presenting to an ophthalmology department usually describe a different pattern of symptoms from those given by the authors and therefore may have an alternative differential diagnosis. In this group of patients, visual symptoms and not headache are often the predominant feature. Indeed, a considerable proportion of patients will be referred because of photopsia alone. As in those presenting with headache, a detailed history is important in reaching a diagnosis.

The first challenge is to document whether the visual disturbance originates from one eye or is a binocular disturbance in a vertical hemifield. Often the patient will struggle to differentiate between the two. The aura of classic migraine is a binocular phenomenon; the uniocular visual disturbance due to retinal migraine is extremely rare and should be regarded as a diagnosis of exclusion. In our experience the unusual phenomenon of transient visual disturbance as a presenting feature of temporal arteritis is usually due to a decrease in the vision of one eye ${ }^{2}$ rather than involvement of the vertebrobasilar circulation. ${ }^{3}$

While the aura of classic migraine may certainly occur in the absence of headache, we suggest that this is sufficiently uncommon to merit the consideration of other conditions. In middle aged or elderly patients who do not have a history of similar visual phenomena of migraine, embolic disease should be considered as a likely cause of the visual disturbance; the pattern may be similar to that described by patients who suffer from true migraine. We have seen younger patients who have presented with epileptiform events that produced symptoms mimicking fortification spectra and other visual disturbances normally associated with classic migraine. Occipital lobe arteriovenous malformation was the most common underlying condition in this group.

ANDREW D BROWN Senior house officer in ophthalmology PAUL M DODSON Consultant physician JOHN R AINSWORTH

Birmingham Heartlands Hospital Consultant ophthalmic surgeon

Birmingham B9 5S

Goadsby PJ, Olesen J. Diagnosis and management of migraine. $B M F$ 1996;312:1279-83. (18 May.)

2 Liu GT, Glaser JS, Schatz NJ, Lawton Smith J. Visual morbidity in giant cell arteritis. Ophthalmology 1994;101:1779-85. 3 Thystrup J, Knudsen GM, Mogensen AM, Fledelius HC. Atypical visual loss in giant cell arteritis. Acta Ophthamol 1994;72:759-64.

\section{Care needs to be taken with treatment}

EDITOR,-As pharmacists, we were surprised by Peter J Goadsby and Jes Olesen's recommendation that asthmatic patients who suffer from migraine who are not offered propranolol may tolerate a more cardioselective $\beta$ blocker, such as metoprolol or atenolol, for prophylactic treatment of their migraine. ${ }^{1} \mathrm{We}$ wish to draw attention to the recent reminder from the Committee on Safety of Medicines that "beta-blockers are contraindicated in asthma. Beta-blockers, including those considered to be cardioselective, should not be given to patients with a history of asthma/bronchospasm."2

Furthermore, caution is required in initiating treatment with methysergide despite its effectiveness. It is generally recommended that methysergide should be given under hospital supervision, with three monthly measurements of urea and creatinine concentrations, physical examination, and counselling of the patient. ${ }^{34}$ Treatment should not continue for more than six months without a drug free interval of at least one month for reassessment.

Finally, we wish to reinforce the manufacturer's dosing guidelines for sumatriptan. ${ }^{5}$ Patients who do not respond to an initial $100 \mathrm{mg}$ dose should not take a second dose for the sam attack. Patients who respond initially but whose symptoms return may take a second dose provided that no more than $300 \mathrm{mg}$ is taken in 24 hours.

ANET LOCK Pharmacist DAWN GALLAGHER

Pharmacy Department, Pharmacis

City General Hospital,

Stoke on Trent ST4 6OG

1 Goadsby PJ, Olesen J. Diagnosis and management of migraine. BMF 1996;312:1279-83. (18 May.)

2 Committee on Safety of Medicines and Medicines Control Agency. Warning - beta-blockers contra-indicated in Agency. Warning - beta-blockers contra-indicated Lance J. Treatment of migraine. Lancet 1992;339:1207-9.

3 Lance J. Treatment of migraine. Lancet 1992;339:1207-9. London: Pharmaceutical Press, 1993.

5 Imigran. Data sheet compendium. London: Association of British Pharmaceutical Industry, 1995.

\section{Low dose aspirin may be used for prophylaxis}

EDITOR,-Peter J Goadsby and Jes Olesen do not mention the use of low dose aspirin to prevent migraine. ${ }^{1}$ Migraine is common in pregnancy, both in women with a history of migrainous headaches and as a phenomenon related to pregnancy in women without such a history Sometimes the presentation may be dramatic, with hemiplegic migraine. Migraine accounts for almost a third of neurological problems encountered in our obstetric medicine clinic and is the diagnosis in about $4 \%$ of all women referred. ${ }^{2}$

Because drugs such as $\beta$ blockers and valproate may have adverse effects on the fetus, and because of the lack of data concerning the safety of drugs such as pizotifen, we use low dose aspirin (75 mg daily) as prophylaxis for pregnant women with frequent or severe attacks of migraine. This dose has been shown to be without adverse effects on the fetus. ${ }^{3}$ Over the past two years we have seen 37 women with headache or migraine in pregnancy. Of these, 28 were given preventive treatment with aspirin and 22 reported subjective improvement. We have yet to confirm our findings with a placebo controlled trial, but because low dose aspirin is safe and effective in migraine that complicates pregnancy it remains our first line agent. $\beta$ Blockers are reserved for resistant cases without contraindications.

Several studies have shown the efficacy of aspirin for prophylaxis against migraine, as has previously been pointed out in a letter to the BMF. ${ }^{4}$ In a large placebo controlled trial Buring et al found a significant reduction $(7.4 \% v 6.0 \%)$ in the rate of recurrence of self reported migraine in male physicians receiving aspirin $325 \mathrm{mg}$ on alternate days." The British doctors' trial reported a $29 \%$ reduction in the occurrence of migraine in the group randomised to take $500 \mathrm{mg}$ aspirin daily compared with those who avoided aspirin. ${ }^{4}$ Smaller prospective clinical studies have shown reductions in the frequency, severity, or duration of migraine when aspirin is used prophylactically in doses from 80 to $1300 \mathrm{mg}$ daily. A double blind crossover study of 28 patients (including 23 women) that compared aspirin with metoprolol found a significant reduction in the frequency of attacks with aspirin, although metoprolol was more effective.

The rationale for using aspirin to prevent migraine is that platelets contain most of the plasma serotonin and that platelet antagonists, by decreasing platelet aggregability, may lead to changes in plasma serotonin which may influence vasoconstrictive serotonin receptors. This may be particularly pertinent in pregnancy, which is associated with activation of platelets.

CATHERINE NELSON-PIERCY Senior registrar in obstetric medicin MICHAEL DE SWIET Consultant physician

Institute of Obstetrics and Gynaecology

Queen Charlotte's and Chelsea Hospital for Women

Queen Charlotte's

1 Goadsby PJ, Olesen J. Diagnosis and management of migraine. $B M F$ 1996;312:1279-83. (18 May.)

2 Nelson-Piercy C, de Swiet $M$. Obstetric physicians: are they needed? The workload of medical complications in pregnancy clinic. $f R$ Coll Phys 1996;30:150-4.

3 CLASP (Collaborative low-dose aspirin study in pregnancy) Collaborative Group. CLASP: a randomised trial of low-dose aspirin for the prevention and treatment of pre-eclampsia among 9364 pregnant women. 1994;343:616-29.

4 Peto R. Treating migraine. BMf 1989;299:517.

5 Buring JE, Peto R, Hennekens CH. Low-dose aspirin for migraine prophylaxis. $¥ A M A$ 1990;264:1711-3.

\section{Authors' reply}

EDrToR,-Andrew D Brown and colleagues are right to point out the different presentation of patients who present to ophthalmology outpatient departments and the importance of thorough review of isolated aura, particularly in older age groups. The diagnosis of migraine, by definition, ${ }^{1}$ implies such a review. 